\title{
Entre la historia y la memoria: un estudio a través del tiempo de la Comunidad kolla de Finca
} \section{Santiago}

Between history and memory: a study during time of the Finca Santiago kolla community

\section{Marina Weinberg}

\section{(2) OpenEdition}

\section{Journals}

\section{Edición electrónica}

URL: http://journals.openedition.org/corpusarchivos/2963

DOI: 10.4000/corpusarchivos.2963

ISSN: 1853-8037

Editor

Diego Escolar

\section{Referencia electrónica}

Marina Weinberg, «Entre la historia y la memoria: un estudio a través del tiempo de la Comunidad kolla de Finca Santiago », Corpus [En línea], Vol. 9, No 1 | 2019, Publicado el 30 junio 2019, consultado el 04 julio 2019. URL : http://journals.openedition.org/corpusarchivos/2963 ; DOI : 10.4000/ corpusarchivos.2963

\section{Este documento fue generado automáticamente el 4 julio 2019.}




\section{Entre la historia y la memoria: un estudio a través del tiempo de la Comunidad kolla de Finca Santiago}

Between history and memory: a study during time of the Finca Santiago kolla community

Marina Weinberg

\section{NOTA DEL EDITOR}

Fecha de recepción del original: 27/08/2018

Fecha de aceptación para publicación: 28/11/2018

1 Los que escucharon hablar a los más viejos, dicen que no siempre reinaron la oscuridad y la pobreza, que hubieron aquí grandes señores, hombres sabios que hablaban con elocuencia, mujeres que parían hijos de ánimo esforzado, orfebres de la madera, de la arcilla y de los metales de paz y de guerra, músicos, pastores de grandes majadas y sacerdotes que sabían conjugar los excesos divinos, gente que edificaba sus casas con piedra. Pero eso ocurrió en otros tiempos, antes de que el Diablo, al arribo de los invasores, desguarneciera la puna arreando a este pueblo hacia los valles y llanuras bajas, donde crece el bosque. (Héctor Tizón, 1969, p.9)

\section{Presentación}

2 El presente trabajo ${ }^{1}$ tiene como fundamento empírico y conceptual una investigación de archivos históricos, llevada a cabo en la comunidad kolla de Finca Santiago, ubicada en el departamento de Iruya, provincia de Salta. ${ }^{2}$ La misma está compuesta por cuatro comunidades denominadas Colanzuli, Volcán Higueras, Isla de Cañas y Río Cortaderas. Este territorio tiene una extensión total de 125.459 hectáreas y teniendo en cuenta su 
disposición, cubre una gran variedad ecológica. Finca Santiago fue la primera comunidad indígena en recibir el reconocimiento legal y la devolución territorial posterior a la Reforma Constitucional de 1994. El objetivo del presente análisis es mostrar una serie de documentos hallados en relación a la historia de la comunidad, entre fines del siglo XIX y a lo largo siglo XX. De alguna manera, se considera que dichos archivos permiten ahondar en una historia de disputa territorial y de lucha por reconocimiento estatal. A 20 años de dicho acontecimiento, va en este trabajo un homenaje a la incansable lucha de los pueblos indígenas de nuestro país, y en especial a la comunidad de Finca Santiago.

Finca Santiago alberga en su extensión una región bien definida de tierras altas y una de tierras bajas, que unen prácticamente el pueblo de Iruya con la ciudad de San Ramón de la Nueva Orán. (Mapa $\mathrm{N}^{\circ} 1$ ). La primera es una zona de Puna, que en algunos lugares supera los $3800 \mathrm{mts}$. sobre el nivel del mar, por lo que es extremadamente seca, con vientos y sol muy fuertes; predomina el denominado 'desierto andino' y la vegetación es de pastos y arbustos que varían de acuerdo a las características ecológicas locales. Aquí reside la comunidad de Colanzuli. Las tierras bajas, donde se encuentran las comunidades de Isla de Cañas y Río Cortaderas, se componen de bosques y selva subtropical (yungas), se trata de una zona húmeda y las temperaturas durante el verano son extremadamente altas. A pesar de que las "...diferencias estacionales son más marcadas en las tierras bajas y húmedas que en las tierras altas y secas del extremo puneño" (Reboratti, 1998, p. 37), en ambos casos las estaciones están bastante determinadas por las pluviaciones, siendo el verano una época de fuertes precipitaciones y el invierno completamente seco. Finalmente, en la transición entre ambos sectores hay un bosque de montaña, ubicado a alrededor de 3000 m.s.n.m., en donde se halla la comunidad de Volcán Higueras (Weinberg, 2004a; 2004b).

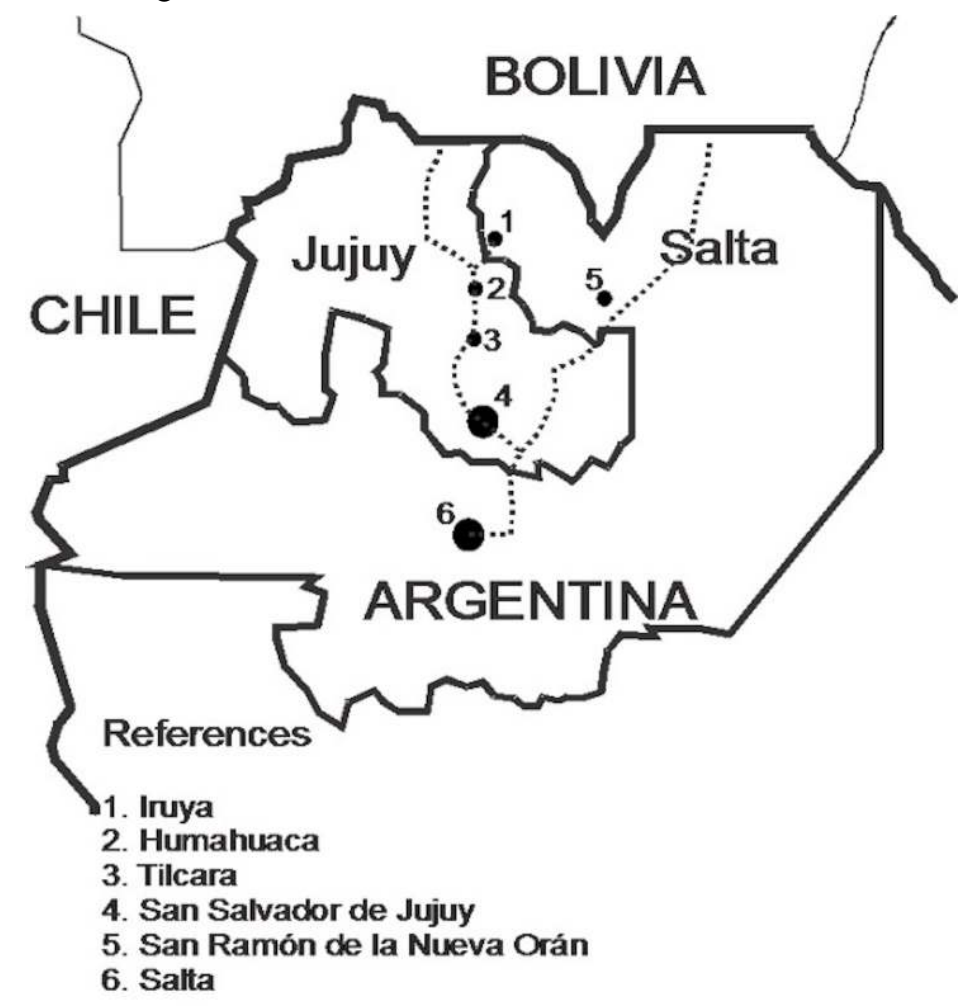

Mapa $\mathrm{N}^{\circ} 1$ (Weinberg, 2013, p.17). 
4 A lo largo del proceso de recolección de materiales de archivo, se tomó la decisión metodológica de seleccionar y recuperar solamente aquellos documentos que hiciesen mención específicamente al territorio que se denomina "Finca Santiago" o bien a las comunidades o parajes que lo conforman y hasta la actualidad mantienen sus nombres (Colanzuli, Higueras, Matancillas, Río Cortaderas, entre otros). (Mapa $\mathrm{N}^{\circ} 2$ ).

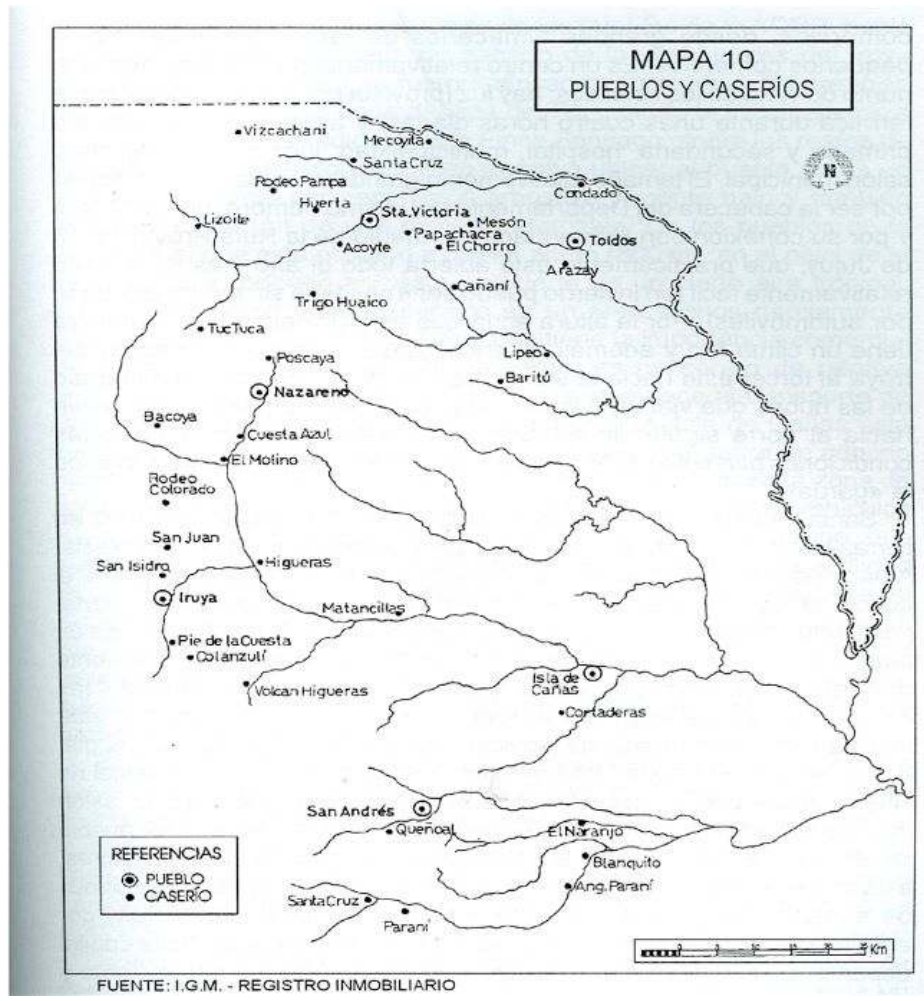

Mapa N² (Reboratti, 1998, p.111).

\section{Un poco de historia}

El noroeste argentino fue una región de poblamiento multiétnico y aún subsisten los debates relacionados con el origen y filiación de las parcialidades que lo habitaban, aunque existe coincidencia en relación a los límites geográficos de ocupación omaguaca (Sica 2016; Zanolli 2005). Luego de la derrota y "pacificación" de los indígenas de la Puna, se crea la "Gobernación y Provincia de Tucumán, Juríes y Diaguitas" en el año 1563, dependiente del distrito de la Real Audiencia de Charcas, estableciéndose allí grandes encomiendas (Madrazo, 1982; Sánchez, 2003; Sánchez y Sica, 1990).

Hasta fines del siglo XIX se sucedió un proceso de privatización de la propiedad de la tierra, el cual en algunos casos llegó hasta principios del siglo XX. La pérdida territorial indígena respondió a una variedad de motivos (fiscalización, enfiteusis, remates públicos, ventas, etc.) que implican considerar la complejidad del proceso (Fandos 2014). Desde 1870 las tensiones entre el campesinado y las élites locales se tornaron en un conflicto más profundo y complejo. Las protestas solían estar motivadas contra "...los abusos cometidos en la recaudación de impuestos o en un excesivo cobro de arriendos" (Paz 1992, p. 219) y a partir de ese momento se reorientaron hacia la recuperación de las tierras ocupadas ancestralmente. Este movimiento culminó con el levantamiento de Quera, cuyo epicentro fue la Finca Cochinoca y Casabindo, y fue protagonizado por sus 
arrendatarios. El mismo terminó en una sangrienta matanza de los indígenas a manos del ejército. Bajo ningún punto de vista se puede analizar este evento como un hecho aislado. En este sentido, algunos autores han propuesto que si bien el estallido sucede entre los años 1872 y 1875 , la batalla expresa un largo proceso de opresión en un contexto en el cual las comunidades indígenas querían recuperar la tenencia de su territorio así como terminar con el sistema de arrendamientos (Paz, 1989). En esta dirección, Rutledge avizora una posible relación de la batalla de Quera con un levantamiento en el altiplano boliviano, ocurrido también durante las últimas décadas del siglo XIX. De esta manera, se descartaría la idea del aislamiento geográfico de la batalla, reforzándose la hipótesis de “...considerar legítimamente a la rebelión de la Puna como un episodio de un proceso más general de descontento rural que afectó a un gran sector de los Andes centrales en las tres últimas décadas del siglo XIX" (1992, p. 251).

\section{Territorio y propiedad: apropiación y expropiación ${ }^{3}$}

Si bien no se hará aquí un análisis pormenorizado sobre los traspasos de la posesión de las grandes propiedades de la región, hubo un fuerte proceso de "pérdida de las tierras de manos indígenas [así como de] desintegración paulatina de las sociedades nativas. (...) El siglo XVIII trajo aparejado mayores presiones económicas sobre las sociedades indígenas, producto principalmente de la política fiscal implantada entonces y de cambios en el orden de la producción, el trabajo y el comercio" (Teruel y Fandos, 2009, p. 237). Sabemos también que "luego de la derrota y pacificación de los indígenas de la Puna a fines del siglo XVI, se establecieron algunas grandes encomiendas en el área" (Rutledge, 1992, p. 241). Y ya con el establecimiento del dominio español "la zona de altura fue dividida en tres grandes Mercedes, una de las cuales se constituye en la gran Finca Rodero/Negra Muerta, que más tarde dio origen a Finca Santiago" (Hocsman, 2000, p. 54). (Mapa N³). Más tarde, este territorio quedó dividido entre Salta y Jujuy y finalmente lo que conocemos hoy como Finca Santiago, dentro de la parte este del territorio salteño. En 1837 se inicia la guerra con Bolivia y estas tierras son invadidas nuevamente. Al finalizar dicho enfrentamiento, toda la extensión volvió a pertenecer al territorio argentino.

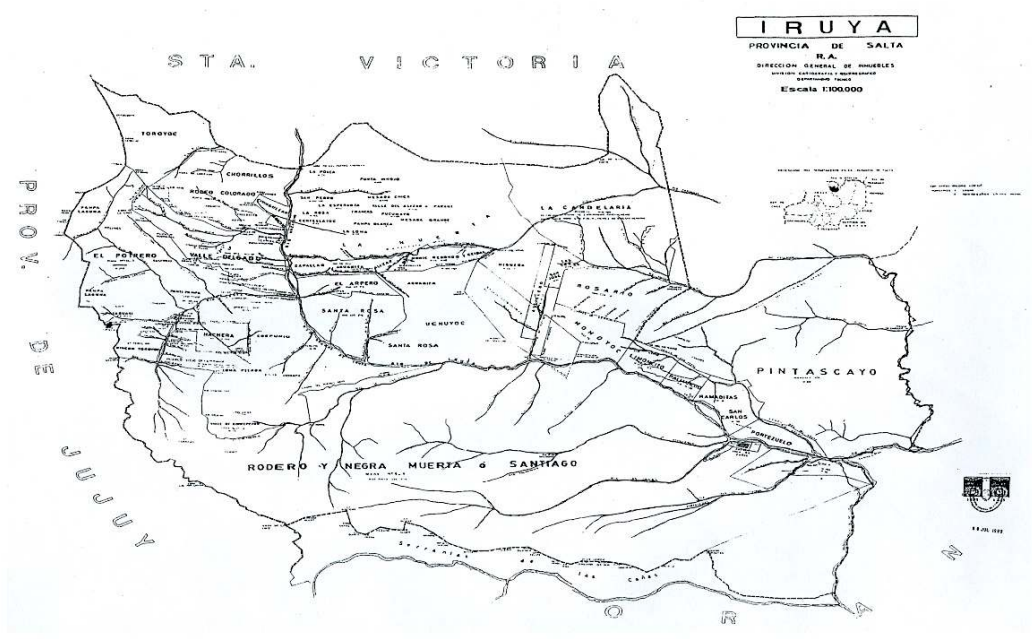

Mapa ํ3 (Hocsman, 2000, p.31). 

conflictos con la poderosa familia Álvarez Prado (Fandos, 2015). Esta autora señala que la familia recibía arriendos incluso por fragmentos de tierras que eran fiscales. En 1883, según la autora, 'ciudadanos', 'vecinos' y 'naturales' de Miyuyoc, Chaupe Rodeo, Negra Muerta, Pueblo Viejo, Aparzo, Varas y Horno Cal” (todas localidades dentro de lo que se reconoce hoy como Finca Santiago) presentan solicitudes de deslinde, ya que consideraban que estas tierras habían estado comprendidas en las de comunidad indígena, citando textualmente párrafos de las Leyes de Indias (Fandos, 2015, p. 14). Si bien eventualmente se convino una "relación contractual" entre los Álvarez Prado y algunos arrendatarios, el conflicto quedó latente.

Luego de un traspaso del Banco Hipotecario Nacional a un propietario de nombre Francisco A. Terrones, encontramos en 1908 la Finca inscrita por Miguel Fleming y Robustiano Patrón Costas, "quien ejerciendo la más absoluta coacción se proveía de esta población campesina y arrendataria como mano de obra para su empresa, el Ingenio San Martín de Tabacal" (Fandos, 2015, p. 15). En 1926, le venden la finca al hermano de este último (Juan Patrón Costas). Por lo tanto, desde principios hasta mediados del siglo XX, la familia Patrón Costas fue propietaria de la totalidad de la extensión de las tierras que conforman Finca Santiago, así como de otras fincas vecinas; y fue también uno de los propietarios mayoritarios del ingenio San Martín del Tabacal, hasta su quiebra. En muy corto tiempo comenzaron a cobrar arriendo a las poblaciones originarias que allí vivían.

La estrategia de concentración de tierras por parte de la familia Patrón Costas tenía como principal objetivo el acceso continuo a un reservorio de mano de obra en todas las zonas satelitales al Ingenio. Al haberse visto forzados como arrendatarios de sus propios territorios, las poblaciones locales debieron subsumirse como fuerza de trabajo al servicio de la zafra, y sumarse así al proceso estudiado por Bisio y Forni (1976) de desarrollo regional de mercados de trabajo rural satelizados con su "inevitable correlato" de precariedad laboral. Así como también observar que

11 La primera relación con los indígenas, cuasi servil, adquiere con el desarrollo de formas más capitalistas de producción características de trabajo asalariado, pero subsistiendo diferencias de remuneración y tratamiento con los trabajadores cristianos. La postergación jurídica, cultural y política de los aborígenes permitió su explotación económica y todo tipo de abusos (1976, p. 39).

12 En todos los casos, los salarios recibidos eran siempre menores a los precios de las mercaderías que se ofrecían en las proveedurías dentro del Ingenio y en el sistema de almacenes que se iba instalando en las localidades de la región, también propiedad de la misma familia; por lo que se generaba un sistema de enganche por deuda que garantizaba y perpetuaba la necesidad de los pobladores de acudir, año tras año, a la zafra.

13 A diferencia del resto del país, la región de haciendas del noroeste argentino, quedó mayormente relegada del desarrollo capitalista. La presencia de ferrocarril, de industrias y de trabajo asalariado era baja, por lo que la población quedó reducida casi exclusivamente a una economía de subsistencia (Bisio y Forni, 1976). "Lo primero que se necesitaba era conectar a esa población a la circulación monetaria” (Reboratti, 1998, p. 90), por lo que se comenzaron a introducir mercaderías inexistentes en la zona (a precios más elevados que en otras regiones) y a prestar servicios que los campesinos debían pagar con dinero. Por lo tanto, se vieron obligados a ofrecerse como mano de obra en el Ingenio San Martín de Tabacal para poder percibir una cantidad de dinero (siempre muy escasa), 
que les permitiese ir saldando las deudas que habían contraído involuntariamente, tanto por causa de la apropiación de sus territorios, así como de los gastos que realizaban en los almacenes. ${ }^{4}$ En este caso, vemos entonces una complementariedad de sistemas donde confluían tanto trabajadores provenientes de áreas "satelizadas", proveedoras de mano de obra estacional (Bisio y Forni, 1976), como pobladores de Finca Santiago que debían generar ingresos monetarios para pagar por sus arriendos.

(anca Santiago S.A., compuesta inicialmente por Robustiano Manero y Manuel Quirós, a la que luego se sumó Daniel Coto. No se realizó ningún tipo de inversión, sino que se mantuvo un sistema de extracción de rentas a los ocupantes y se inició una tala indiscriminada del bosque añejo (en las tierras bajas, entre las comunidades de Río Cortaderas e Isla de Cañas), que se sostuvo a lo largo de casi cinco décadas. Esta transacción y cambio de dueños no presentó modificaciones en el cotidiano ya que al conformar una gran masa de mano de obra cautiva, los pobladores debieron seguir yendo al Ingenio para poder obtener dinero suficiente que les permitiese afrontar los pagos exigidos. ${ }^{5}$

Por otra parte, en 1990, quebró el Ingenio San Martín del Tabacal (emplazado fuera de los límites de Finca Santiago) y, seis años más tarde, la empresa norteamericana Seabord Corporation se hizo cargo del mismo, manteniendo el funcionamiento hasta la actualidad.

En octubre de 1994 se sancionó en el Congreso Nacional la ley 24.242 de expropiación, que restituyó al pueblo kolla de Finca Santiago su territorio, y fue a partir de ese momento que la Finca comenzó a ser administrada por el Consejo Kolla. Luego de concretada la expropiación, a comienzos de 1997, la Comunidad constituida por los cuatro ayllus ${ }^{6}$ (Colanzuli, Volcán Higueras, Río Cortaderas e Isla de Cañas) sancionó el Estatuto General que rige en la totalidad del territorio hasta la actualidad. Dicho Estatuto funciona como ley "madre", en la cual se establecieron los principios básicos sobre los que se apoya la comunidad; a la vez, cada ayllu cuenta con un reglamento interno. El Consejo Kolla de Finca Santiago está integrado por doce representantes de los cuatro ayllus (tres por cada uno), los cuales son a su vez miembros de los Consejos locales. Estos últimos, también están conformados por doce integrantes. Todos ellos están presididos por un coordinador general (Weinberg, 2004a; 2004b).

17 Finalmente, el 19 de marzo de 1997, el entonces Presidente Carlos Menem hizo entrega de la posesión formal de las 125.000 hectáreas de tierras comunitarias y a fin del año 1999 les fue entregado el título de propiedad de sus tierras, a nombre de la Comunidad Indígena del Pueblo Kolla de Finca Santiago (Ver Anexo, Tabla Nº 1 , Propietarios de Finca Santiago 1894-1997).

Durante la investigación que nos proporcionó la información que volcamos en este estudio, encontramos boletos de compra-venta y planos de agrimensura asociados a Finca Santiago desde fines del siglo XIX y hasta la devolución final a la comunidad en el año 1997.

19 La Finca a la que referimos tiene una extensión de casi 125.459 hectáreas, superficie que se mantiene (aunque con algunas pequeñas modificaciones en sus límites debido a mensuras que se realizaron en diversas ocasiones) bajo el nombre de "Rodero/Negra Muerta" o "Santiago", desde 1926. Comenzamos este análisis entonces, a partir del primer documento encontrado en los Libros de Títulos Generales de la Dirección de Inmuebles de la provincia de Salta, que hace referencia explícita a este territorio. 
20 La información inicial que tenemos de la Finca es un plano topográfico (levantado en 1889), en el cual se la denomina "Rodero y Negra Muerta", y la ubica en las provincias de Salta (departamento de Iruya) y Jujuy (departamento de Humahuaca) y figura como perteneciente a Don Vicente García (Ver Anexo, Mapa Nº4, 1889). Luego, analizamos el primer boleto de compra-venta (1894) en el cual figura el Banco Hipotecario Nacional como propietario. Se nos escapa entonces la información a través de la cual el territorio llega hasta esa institución. La propiedad, vendida a Francisco A. Terrones, consta de 170.500 hectáreas (en el departamento de Iruya), de las cuales 125.459 son las que finalmente se agrupan bajo el nombre de Finca Santiago; se desconoce qué sucedió con este desmembramiento. El valor que se paga por la misma es de $\$ 70.000+\$ 1140,2$ por “derechos", lo que hace un total de $\$ 71.140,2$.

21 Nos volvemos a encontrar con un plano, fechado en septiembre 1900, "de la propiedad 'Santiago' (departamento de Iruya), de Don José Mórtola” con el nombre del agrimensor ilegible (Ver Anexo, Mapa N5, 1900). En el siguiente boleto de compra-venta, con fecha de 1906, regresamos a Don Terrones como propietario, vendiéndole el territorio a Miguel Fleming y a Juan Patrón Costas. El mismo mantiene su denominación ("Rodero y Negra Muerta") pero a diferencia del plano anterior, figura ubicado en los departamentos de Orán e Iruya. Se trata de un a venta con hipoteca y el valor de la transacción es de $\$ 60.000$ + $\$ 300$ por estampillado y $\$ 300$ por papel de multas, lo que hace un total de $\$ 60.600$.

Dos años más tarde, en 1908, se mantiene la "venta con hipoteca" (lo que presumimos mantenía un valor más bajo de la propiedad en relación a su gran magnitud) y la Sociedad "Patrón Costas y Cía" representada por Fleming y Robustiano, se la vende al hermano de este segundo, Juan Patrón Costas. El valor asciende un poco respecto a los anteriores: su total es de casi $\$ 400.000$ (con hipoteca y estampillado incluido). Para este entonces observamos un plano (levantado en 1908) de la Finca "Rodero o Negra Muerta" o "Santiago" propiedad del señor Juan Patrón Costas, situada en el departamento de Iruya (Ver Anexo, Mapa Nº, 1908).

23 En el año 1926 la compañía bajo el mismo nombre ("Patrón Costas y Cía.") pero esta vez representada por Juan, le vende las 125.459 hectáreas a la Sociedad Anónima Compañía Territorial del Norte (Juan Mosciano e Higinio Rantangelo) por $\$ 400.000$. El salto cualitativo respecto al valor se da en la transacción siguiente, en el año 1928, en donde estos últimos venden la Finca a la Sociedad Limitada "Manero y Quirós" por valor de $\$ 2.500 .000$. Si bien no podemos realizar grandes aseveraciones ya que no se ha investigado en profundidad, se evidencia que hubo una ganancia desmedida en esta venta ya que prácticamente se sextuplica el valor del territorio entre 1926 y 1928.

24 Entre los años 1951 y 1983 la propiedad (bajo el nombre de "Santiago" o "Rodero y Negra Muerta" en los departamentos de Iruya y Orán) se vende dos veces, se disuelve la Sociedad propietaria y hay una suerte de transferencia a herederos, aunque siempre reconocemos los mismos apellidos implicados (Coto, Quiroz, Manero); y los valores oscilan entre $\$ 2.534 .358$ y $\$ 1.275 .000$. Según nuestro conocimiento, estos propietarios son quienes inician la tala que destruye casi por completo el bosque ubicado en la zona baja de la Finca (principalmente en Isla de Cañas). Inclusive, en un boleto del año 1959, se explicita que la "Sociedad Finca Santiago tiene por objeto la explotación forestal".

En el año 1997 se inicia el trámite de "Expropiación irregular" a favor de la Comunidad Indígena del Pueblo Kolla de Finca Santiago, allí se establece que "el territorio es de posesión y dominio ancestral". Finalmente, en el año 1999, se inscribe la propiedad y se 
da por finalizado el traspaso. Cabe acotar que si bien se refiere a "expropiación", el gobierno nacional pagó a los últimos propietarios (firma Finca Santiago S.A.) la suma de $\$ 5.020 .000$, entregada en tres cuotas.

Luego de hacer un prolijo repaso por los diferentes propietarios que tuvo este territorio, habiendo podido además reconstruir las denominaciones, valores y medidas que se le fueron otorgando, resulta por demás abrupto recordar que en estas 125.458 hectáreas había una población fija que fue cautiva de los diferentes apropiadores. ${ }^{7}$ No contamos con información precisa de los primeros propietarios, pero sí podemos afirmar que ya desde 1906, bajo el mando de la familia Patrón Costas, los pobladores de la región debieron iniciar trabajos forzados para desmontar lo que luego fue la inmensa plantación de caña que diera origen a la fundación de una de las empresas más poderosas de la historia argentina. Al mismo tiempo, durante casi cinco décadas en que el Ingenio requirió mano de obra de manera masiva, no pudieron escapar a dicha actividad ya que debían pagar arriendo. Con la venta de la Finca en la década de los cincuenta a la Sociedad "Manero Quirós", este pago no se suspendió. Una parte de la población mantuvo sus traslados al Ingenio y otros se sumaron a las actividades que requería la empresa maderera.

La comunidad kolla de Finca Santiago hace poco más de dos décadas recuperó su territorio ancestral. Desde ese momento, ha comenzado un dificultoso proceso de organización política, procurando la representación de las cuatro comunidades contenidas en este extensísimo territorio. Como es de imaginar, no ha sido sencillo y los actores intervinientes se han ido multiplicando con el correr de los años.

\section{Los censos y los pueblos}

El análisis del presente apartado se realizó a partir de los Censos Nacionales de los años 1869 y 1895 (ambos nominales). ${ }^{8}$ Teniendo en cuenta que se trata de una zona rural, y que inclusive hoy el acceso no es tan sencillo, resulta por demás complejo establecer los límites y las referencias a las que se alude bajo las distintas denominaciones cuando se refiere a los lugares. En ese sentido, más allá de las salvedades, la información aquí desplegada permite obtener un acercamiento demográfico a la zona estudiada con profundidad histórica de poco más de un siglo.

En el Censo Nacional de 1869 figuran trece distritos dentro del departamento de Iruya: Casa Grande, Colansuli, Higueras, Iruya, San Pedro, Tipayos, Hucoyor, Valle Delgado, Biscarra, Iscuya, Volcán, Potrero y Porongal; mientras que en el año 1895, se mantienen diez pero se subdividen internamente: Casa Grande (incluye al "pueblo" Colanzuli), Higueras, Iruya, San Juan, San Pedro, Tipayoc (incluye al "pueblo" San Isidro), Uchuyoc, Valle Delgado, Viscarra e Iscuya (incluye a los "pueblos" Cañas, Sala Iscuya, San Antonio y Volcán Higueras). Podemos suponer que si en la actualidad resulta confuso establecer límites claros entre los diversos parajes que están dentro del territorio trabajado, en el siglo XIX resultaba aún mucho más difícil hacerlo.

En el Censo Nacional del año 1895 existe un número elevado de población permanente en las comunidades de las "tierras altas" (nos referimos a seis distritos: Cañas-Izculla, Colanzuli, San Antonio, Sala Iscuya, Tipayoc y Volcán Higueras). Ya en aquel relevamiento, eran reconocidas dos de las comunidades con los que trabajamos en la actualidad (Volcán Higueras y Colanzuli) y las otras, de las cuales algunas se encuentran fuera de los límites trabajados (por ejemplo San Antonio, Uchuyoc y Tipayoc), han sido 
lugares de nacimiento y residencia de familias que actualmente viven en Finca Santiago. ${ }^{9}$ Al mismo tiempo, se han mantenido "puestos" familiares utilizados para la práctica de ganadería trashumante, aprovechando las diferencias altitudinales a las que se hizo referencia anteriormente.

Teniendo en cuenta que Colansuli (actualmente Colanzuli) es el único distrito que hallamos en ambos Censos, a modo de referencia podemos decir que en el año 1869 hubo 178 censados y para el año 1895 habían aumentado a 211. En la actualidad, su población asciende aproximadamente a 700 personas. En Volcán Higueras, aparecen censados 391 habitantes en 1895 y actualmente viven allí menos de 300. Esta merma podría ser resultado de las migraciones a las que se hizo mención, relacionadas con el trabajo en el Ingenio San Martín de Tabacal y con el aumento de mejoras infraestructurales en la comunidad de Isla de Cañas (ubicada en las tierras bajas, y fundada como municipio en el año 1974). Hasta la actualidad, Volcán Higueras no tiene acceso por camino carretero, se puede acceder tanto desde la zona alta, a través de Palca de Aparzo (Jujuy), saliendo de Humahuaca; desde Colanzuli a través del lecho del río Iruya (en la época seca) y finalmente, desde la zona baja (Isla de Cañas y Río Cortaderas), por el lecho de los ríos.

Podemos decir entonces que la mayor parte de la población que ocupa actualmente los ayllus de la parte baja (Río Cortaderas e Isla de Cañas), proviene de las zonas altas de la Finca. Este desplazamiento hacia las yungas tiene estrecha relación con el movimiento poblacional que generó la fundación del Ingenio San Martín del Tabacal a principios de siglo XX. Una de las principales vías de comunicación entre las comunidades de la región ha sido la "playa" (lecho) del río Iruya (que permite unir Colanzuli con Isla de Cañas) y con la creación del Ingenio, se convirtió en una de las rutas más utilizadas para llegar. Por lo tanto, luego de algunos años de "bajar" a trabajar a la zafra (desde las primeras décadas del siglo XX), algunas familias fueron reubicándose en estas regiones más húmedas. Finalmente, la fundación del municipio de Isla de Cañas, por la infraestructura que ofreció (desmalezamiento del monte, planificación del poblado, instalación de red eléctrica, construcción del hospital, escuela, camino carretero con salida a la ciudad de Orán), terminó de atraer a aquellos que ya habían comenzado el recorrido.

Son muy pocos los casos en que la nacionalidad de los censados no es argentina, así como también casi la totalidad son nacidos en la provincia de Salta. De los 211 pobladores de Colanzuli en el año 1895, solo ocho eran jujeños y tres bolivianos, y de Volcán Higueras, sobre 391, hay 25 jujeños y un boliviano. Es decir, que a fines del siglo XIX no había habido gran afluencia extranjera o ajena a la zona.

Otra de las preguntas observadas para el año 1895 fue la referida a la posesión de "propiedad raíz". En Volcán Higueras ninguno de los 391 censados figura como propietario, mientras que de los 211 de Colanzuli sí encontramos algunos casos. Teniendo en cuenta que en el instructivo decía: "Deberá anotarse como que posee propiedad raíz, a todo el que sea propietario de algún terreno, campo, casa, concesión de colonias y demás", queda la duda de cómo esos casos habrán podido demostrar la titularidad sobre sus tierras. $\mathrm{O}$ si simplemente respondieron de manera afirmativa al censista, sin mediar documento.

Exceptuando el distrito de Cañas (Izcuya), en donde encontramos diez "sirvientes" sobre una población total de 33 personas, en el resto de los lugares trabajados casi la totalidad de los adultos (mayores de 14 años) figuran como "Criadores", "Labradores" e "Hilanderas", unos pocos "Comerciantes", "Teleros" y "Ornaleros" y dos casos curiosos de 
"Curanderas", halladas en los distritos de Tipayoc y Colanzuli (esta segunda de origen boliviano).

Finalmente, en el Libro de Catastro de la Propiedad Mobiliaria del Departamento de Iruya, reformado en $1875^{10}$, encontramos "Propietarios" por ubicación (Partido y Finca), identificados con la cantidad de cabezas de ganado y contribución monetaria por las mismas. En el mismo, se presenta una gran mixtura respecto a las denominaciones y circunscripción de las localidades, ya que se superpone con la información relevada en los Censos Nacionales. Como "Partidos" figuran los denominados "Distritos" en los Censos Nacionales: Uchuyoc, Vallegrande, Tipayoc, Viscarra, San Pedro, Casagrande, Volcán, Potrero, Porongal, Iruya, Isculla, Colanzuli; y dentro de estos, una subdivisión en "Fincas": Higueras, Papahuaico, Higueras, Isculla, Varas, Pueblo Viejo, Viscarra.

\section{La Iglesia y la Comunidad ${ }^{11}$}

En este apartado se trabaja material documental mayormente en forma de notas, intercambiadas entre miembros de las comunidades y representantes eclesiásticos. La Iglesia tuvo un rol muy activo e interpersonal, no solo como generadora sino receptora de peticiones por parte de la comunidad. Inclusive, como se verá en algunas de las notas encontradas, se superpuso la incumbencia de ambas instituciones, obteniendo respuestas más inmediatas por parte de la Iglesia.

Como en el resto del trabajo, se decidió tomar aquí aquel material que hiciese referencia a las comunidades que se encuentran dentro de los límites actuales de Finca Santiago o bien a aquellas con las que estas tienen algún vínculo. Como fue indicado anteriormente, hay varios parajes que se encuentran fuera de los límites mensurados de la propiedad, pero de los cuales provienen algunos pobladores o mantienen allí sus puestos familiares, relacionados con la práctica de la ganadería trashumante que los impulsa a desplazarse para la veranada e invernada de ganado entre terrenos con altitud variada.

A lo largo de la investigación se encontraron informes de visitas de misiones (1916, 1937, $1939,1950)$, pedidos para construcción de capillas $(1859,1952,1963)$, pedidos de partidas de nacimiento $(1951,1957)$ y pedidos de visitas a las comunidades $(1950,1951)$.

Listado de documentos revisados

\begin{tabular}{|l|l|l|l|l|}
\hline & Destinatario & Procedencia & Fecha & Motivo \\
\hline 1 & - & $\begin{array}{l}\text { Palca de Isculla } \\
\text { Anejo Curato de } \\
\text { Iruya }\end{array}$ & $03 / 09 / 1859$ & $\begin{array}{l}\text { Informe - Permiso para } \\
\text { trabajar en una capilla nueva }\end{array}$ \\
\hline 2 & - & - & 1916 & $\begin{array}{l}\text { Informe de visitas canónicas } \\
\text { de las Parroquias }\end{array}$ \\
\hline 3 & $\begin{array}{l}\text { General } \\
\text { Monseñor Carlos M. } \\
\text { Cortés }\end{array}$ & Salta & $14 / 02 / 1937$ & $\begin{array}{l}\text { Informe de misiones en los } \\
\text { departamentos de Santa } \\
\text { Victoria e Iruya }\end{array}$ \\
\hline
\end{tabular}




\begin{tabular}{|c|c|c|c|c|}
\hline 4 & $\begin{array}{l}\text { Ilustrísimo Sr. } \\
\begin{array}{l}\text { Monseñor Carlos M. } \\
\text { Cortés }\end{array}\end{array}$ & San Pedro de Iruya & $31 / 04 / 1939$ & Informe de misiones \\
\hline 5 & $\begin{array}{l}\text { Sr. Párroco del } \\
\text { departamento Orán o } \\
\text { Franciscano }\end{array}$ & Limoncito & $20 / 09 / 1950$ & $\begin{array}{l}\text { Pedido de visita de un } \\
\text { sacerdote }\end{array}$ \\
\hline 6 & Rdo. Párroco de Orán & Salta & $24 / 10 / 1950$ & $\begin{array}{l}\text { Autorización de la solicitud } \\
\text { anterior }(20 / 09 / 1950)\end{array}$ \\
\hline 7 & $\begin{array}{l}\text { Diputado Provincial Don } \\
\text { Luis Martino }\end{array}$ & $\begin{array}{l}\text { San Antonio de } \\
\text { Iruya }\end{array}$ & $18 / 12 / 1950$ & $\begin{array}{l}\text { Pedido de visita de un } \\
\text { sacerdote }\end{array}$ \\
\hline 8 & $\begin{array}{l}\text { Sr. Vicario General del } \\
\text { Arzobispado } \\
\text { Don Carlos M. Cortes }\end{array}$ & Iruya & $07 / 02 / 1951$ & $\begin{array}{l}\text { Pedido de partida de } \\
\text { nacimiento en Colanzuli en el } \\
\text { año } 1888\end{array}$ \\
\hline 9 & $\begin{array}{l}\text { Diputado Provincial Don } \\
\text { Luis Martino }\end{array}$ & $\begin{array}{l}\text { San Antonio de } \\
\text { Iruya }\end{array}$ & $17 / 02 / 1951$ & $\begin{array}{l}\text { Pedido de visita de un } \\
\text { sacerdote }\end{array}$ \\
\hline 10 & $\begin{array}{l}\text { Al Exmo. Sr. Arzobispo } \\
\text { Roberto Tabella }\end{array}$ & $\begin{array}{l}\text { Matancillas } \\
\text { Iruya }\end{array}$ & $27 / 06 / 1952$ & $\begin{array}{l}\text { Pedido para que no se destruya } \\
\text { la capilla de Matancillas }\end{array}$ \\
\hline 11 & - & Iruya & $24 / 04 / 1957$ & $\begin{array}{l}\text { Testimonio.- No se encontró la } \\
\text { partida de nacimiento y } \\
\text { bautismo }\end{array}$ \\
\hline 12 & $\begin{array}{l}\text { Monseñor Carlos M. } \\
\text { Cortés } \\
\text { Vicario general de la } \\
\text { Arquidiócesis }\end{array}$ & Isla de Cañas & $04 / 11 / 1963$ & $\begin{array}{l}\text { Informan que ha sido colocada } \\
\text { la piedra fundamental para } \\
\text { una capilla }\end{array}$ \\
\hline
\end{tabular}

Dentro del conjunto de doce notas encontradas, identificamos dos grandes grupos. Por un lado, aquellas producidas desde la Iglesia, que son en su totalidad informes de misiones y visitas a las distintas comunidades de la zona. Por el otro, están los documentos redactados por los mismos comuneros, dirigidos tanto a la jerarquía eclesiástica como a representantes de la política provincial, en los que realizan peticiones de distinta índole, inclusive a veces entrecruzando incumbencias.

41 En las notas 1, 2, 3 y 4 redactadas por los misioneros, se hace referencia explícita a los problemas edilicios que tienen las capillas locales así como también se informa de las "estadísticas" referentes a los servicios religiosos efectuados: bautismos, comuniones, confirmaciones, matrimonios.

\section{Nota 1:}

En este día tres de Septiembre de 1859 habiendo S. Sa Ilma. llegado a este lugar de la Palca de Isculla Anejo Curato de Iruya e informado por los habitantes del lugar que se trataba de trabajar una Capilla nueba por haber destruido un año antes al que havía a llo que un 
pequeño edifico de adove sin reboque y con techo de paja, sirbe provisoriamente de capilla sin altar ni adeveso alguno por consiguiente en el momento de haver llegado.

\section{Nota 2:}

Tengo la suma satisfacción de poder comunicar a Su Señoría Ilustrísima, que se pueden dar por terminadas las misiones en los dos departamentos de Iruya y Santa Victoria. Durante los siete meses de misiones han sido visitados los siguientes centros de población: Iruya, San Pedro, San Isidro, San Juan, Las Higueras, San Antonio, Volcán Higueras, Matancillas, Tipayoc, Santa Victoria, Acoite, Santa Cruz, Lizoite, Nazareno, Pascaya

El resultado de estos trabajos apostólicos es el siguiente: confesaron 3720 personas de las cuales 1538 eran hombres y jóvenes, se distribuyeron 4620 comuniones, se administraron 1344 confirmaciones, 588 bautismos; y se celebraron 353 matrimonios, casi exclusivamente ya existentes desde años sin la bendición de la Iglesia. A pesar de este resultado muy halagador no se han podido destruir algunos muy grandes escándalos p.e. de vivir algunos individuos con la propia hija.

Tal vez la población más funestamente escandalizada desde años es Santa Victoria. Este pueblo ha visto muchos escándalos y actualmente existe allí un número de individuos que se tienen por principales dirigentes de Santa Victoria, y que descaradamente llevan vida plenamente escandalosa de concubinato y adulterio, por no hablar de sus continuas reuniones de embriagueces y otras iniquidades. Algunos de ellos ocupan aún empleos públicos del gobierno de la provincia y de la nación. Pero también se comprenden las tristísimas consecuencias de sus escándalos en la pobre gente y las innumerables víctimas que con sus escándalos y seducción arrastran al abismo.

54 Añado, que los departamentos de Iruya y Santa Victoria han sido terriblemente azotados por la viruela durante el año 1936. La peste fue importada de Bolivia y aún no está del 
todo dominada. Noventa son las víctimas que hasta ahora bajaron al sepulcro. La razón principal por que pudo tomar tanto incremento el mal, que los pobladores de los pueblos y cerros no separan al enfermo de sus viviendas, aislándolo y salvando con cuidado a él y a los demás. La mayor parte de los finados eran niños. Por los muchos trabajos de las misiones y las enormes distancias sólo a muy pocos adultos he podido asistir en su enfermedad de viruela.

Dando infinitas gracias a Dios por el resultado de las misiones saludo respetuosamente a Su Señoría Ilustrísima,

Firma: Padre Armando Tisken

\section{Nota 4:}

San Pedro de Iruya 31,4,39.

Ilustrísimo Señor,

Msr. Carlos M. Cortés,

Ilustrísimo Señor:

Desde el 22 de Setiembre hasta el 15 de Enero andaba yo después de dos años por estos dos departamentos pero tocando solo los puestos centrales: Iruya, Volcán Higueras, Tipayoc, San Pedro, Nazareno, Acoite, Santa Victoria, Lizoite. En esta gira se confesaron casi 2000. Hubo, creo, 400 bautismos, 300 confirmaciones, 54 casamientos...

\section{Firma: Padre Armando Tisken}

Las notas 5, 6, 7, 8, 9 y 10 son peticiones firmadas por integrantes de diferentes comunidades, en las que se hace particular hincapié en lo aisladas que se encuentran y en consecuencia, en la falta de atención que reciben. Así, por ejemplo, declaran que "no da nuestro querido Gobierno de Iruya un Párroco permanente...", o "Poniendo a su conocimiento lo que en este aislado lugar se carese..." y, “... estamos olvidados de tal atención.”. Este intercambio de notas, tan fluido, hace pensar que si bien se reclama por el abandono, existía de todas maneras una relación que los llevaba a seguir insistiendo y esperando respuestas favorables.

\section{Nota 5:}

Limoncito 20 de Septiembre de 1950

Señor Párroco del Depto. De Orán o Franciscano:

De mi atenta consideración y estima: Me dirijo a Ud. soicitándole quiera vicitarnos a esta zona y Finca Santiago; solicitando un permiso del Señor Obispo Diocesano de Salta; en que los vecinos del Punto Tres Morros ${ }^{12}$ se avían dirigido a esa Parroquia pidiendo vendición de un cimiento y más atribución de bautismos de criaturas por ser de que no da nuestro querido Gobierno de Iruya un Parroco permanente como es de costumbre que todos los Departamentos de esta provincia debamos ser atendidos; Porque ay mucha distancia a Humahuaca cuatro días de camino a flete y a Orán seis días de esta zona y maspecimos de rios y caminos escabrosos. Deceamos que esta vicita sea asta el quince de Octubre, pasando de esa fecha, si teme las crecientes que arrojan las rutas. Esperando su digna contestación con el mismo conductor a esta sub-comisaria de Policia y que firman conmigo los vecinos solicitantes y saludo muy atentamente, 


\section{Nota 6:} pueda.

\section{Nota 7:} Zerpa.

Nota 9:

Firman: Rosario Aramayo, CrecencioChauque, RobustianoAramayo, Macedonio Aramayo, Cristina Cruza, Fermín Palacios, Esteban Aramayo, Bartola Rodrigues.

Respuesta a la nota anterior:

\section{Salta 24 de octubre de 1950}

Vuelva al Rdo. Sr. Párroco de Orán autorizándolo, indistintamente a él y a sus Vicarios Cooperadores para atender a los fieles de Limoncito ${ }^{13}$ y alrededores, con las facultades de Misión, inclusa la Confirmación y bendición de matrimonio y dispensa de impedimentos, por cuanto informa el Sr. Pbro. Peralta recientemente regresado de Iruya, que a Limoncito se llega de Orán en medio día de viaje en camión, que siempre va de allí, mientras que de Iruya queda a dos días de viaje a caballo. Agradeciendo desde ya si pueden hacer este favor, se espera información después de haberlo hecho y sea cuando

\section{San Antonio de Iruya Diciembre 18 de 1950}

Al Diputado Provincial Don Luis Martino. Salta.

Los que suscriben en la presente vecinos de esta localidad, se dirijimos ante Ud con el mayor respeto. Poniendo a su conocimiento lo que en este aislado lugar se carese; Para que a su bez sea presentada ante quien corresponda. En primer lugar sugerimos lo siguiente. Aciendo propicia esta oportunidad se nos acuerde una vicita de un SACERDOTE en el mes de MAYO que se ve conveniente por encontrarse todos los havitantes este acuerdo se caresevicitar a los siguientes ANEJOS San Antonio de Iruya, Matancillas y Volcán Higueras.- En los cuales son varios años que vivimos olvidados de la religión cristiana, En todos los Anejos antedichos. Por tal motivo ruega la vecindad se lleve a cabo la presente por su intermedio como representante por nuestro Depto. Y con la plena seguridad de bernosfaborecidos se acompaña el Original de referencia quedando el Duplicado; Esperamos tener respuesta de lo que se alude. Aprovechamos esta oportunidad para saludar con las exprecciones de nuestra consideración mas distinguida.

Firman: Nicomeides Canchi, Eulogio Cañizares, Samuel Ramos, Ignacio Yurquina, Santos Peloc, Santos Florentino Alarde, Cipriano Alarde, AlfonoCanchi, Asencio Canchi, Zacarías Canchi, Virgilio Yurquina, Hipólito Apaza, Mario Zambrano, Senicio Ibarra y Asencio

No se halló la nota en respuesta a este pedido pero sí se encontró el envío efectuado desde la comunidad luego de la recepción de la misma.

San Antonio de Iruya Febrero 17 de 1951.-

Al Señor Diputado Provincial Don Luis Martino. Salta.

Recivimos su atenta en la cual agradecemos su atención de nuestro pedido; De una nota en fecha 18/11/50.- Según su respuesta la cual sugerimos por segunda vez la proximavicita de un SACERDOTE a todos los Anejos del Depto. de Iruya. Segun se informo el tiempo que estamos olvidados de tal atención. Se ruega se efectue tal vicita en el mes de 
Mayo del corriente año. Por ser el tiempo mas conveniente y la mayoria de los habitantes se encuentra en esta, seria conveniente en los primeros dias del mes expresado, A la espera de su valiosa cooperación saludamos con la mayor consideración y respeto esperando sus brevez noticias,

Firman: NocomeidesCanchi, Senicio Ibarra, Alfonso Canchi, Santos Peloc, Manuel Cruz, Bonifacio Chinchilla y Eulogio Cañizares.

\section{Nota 10:}

\section{0).} Ejecutivo), se elevan pedidos de trámites administrativos (como partidas de nacimiento) a las autoridades eclesiásticas; se acude a la Iglesia para hacer un pedido que correspondería dirigir al Registro Civil del pueblo de Iruya.

\section{Nota 8:}

de urgente se me dé testimonio de la partida de mi nacimiento ocurrido en Colanzuli de de urgente, se me dé testimonio de la partida de mi nacimiento ocurrido en Colanzuli de Iruya el 16 de mayo de 1888 - hijo de Bibiano Cruz y de Cruza López de Cruz - para ayudar a la vejez.

94 Saludo al Señor Vicario con toda consideración, 
Firman: Julia Cruz y Julián Cruz ${ }^{14}$ (Colnazuli-Iruya)

\section{Nota 11:}

\section{Nota 12:}

Mons. Carlos M. Cortés

TESTIMONIO - Certifico que registrados los libros del archivo parroquial de Iruya, no se encontró la partida de nacimiento y bautismo de SANTUSA ANAGUA, hija de LiberataAnagua que se denuncia como nacida en Volcán Higueras el día primero de noviembre de mil novecientos. ${ }^{15}$ Para su constancia la firmo y sello en Salta a veinte y cuatro de Abril de mil novecientos cincuenta y siete.

Firma: Carlos A. Acuña - Notario Eclesiástico y Raúl Cadado - Prosecretario/Vicecanciller.

Finalmente, la nota 12 está redactada en Isla de Cañas, cuando aún no tenía status político-administrativo de municipio. Se la describe como una "zona todavía virgen, la zona más rica del Departamento de Iruya", mientras que en la actualidad es la comunidad que tiene acceso más allanado de toda la Finca debido a la explotación forestal que sufrió durante las casi cuatro décadas anteriores a la expropiación, para lo que se abrieron caminos carreteros que permitiesen el acceso de camiones desde la ciudad de Orán. Asimismo, se trata de la comunidad con más comodidades infraestructurales como tendido eléctrico y agua corriente, y oferta de servicios como escuela primaria, secundaria, hospital y policía.

Isla de Cañas, Departamento de Iruya, Noviembre 4 de 1963

Vicario General de la Arquidiócesis de Salta

De nuestra mayor consideración:

Los abajo firmantes, pobladores de Isla de Cañas, Depto. de Iruya, tenemos el agrado de llevar a su conocimiento que en el día de hoy, 4 de noviembre de 1963, ha sido colocada en esta localidad la piedra fundamental de una capilla, dedicada a San Francisco Solano, el gran Apóstol del Tucumán. Esto se debe principalmente a la iniciativa del Padre Oliverio Pellicelli, el primer misionero que penetra en esta zona todavía virgen, la zona más rica del Departamento de Iruya.

Este es el primer paso en el camino del adelanto, que colocará al Departamento de Iruya en un lugar de preferencia entre los Departamentos de la Provincia de Salta. Todos anhelamos a la creación de una colonia agrícola y maderera y esta región surgirá tan sólo bajo la protección de San Francisco Solano, nuestro Apóstol.

105 Además, ponemos en su conocimiento la Comisión pro-templo que se formó hoy mismo al colocarse la piedra fundamental. Presidente: Santos Peloc; Vice: Roberto Yurquina; Secretario: Flavio Palacios; Pro: Hipólito Casiano Apasa; Tesorero: Estanislao Ayarde; Pro: Adrián Canchi; Vocales: Alberto Ayarde, Adrián Ayarde y Pedro Aramayo.

Saludomos al Señor Vicario General en nuestra más alta consideración,"

Firman: Santos Peloc, Pedro Aramayo, Alberto Ayarde, Margarita Peloc, Adrian Chambi, Juana Pastora Peloc, Hipólito Apaza, EmiterioPeloc, Silveria Palacio, Pedro Canchi, Santos Calapeña, Genoveva Yurquina, Justina Zerpa. 


\section{Conclusiones}

108 Este trabajo tuvo como premisa principal la de presentar una serie de documentos hallados en relación a la historia de Finca Santiago a lo largo siglo XX. Al tratarse de una de las primeras comunidades indígenas de Argentina en obtener la devolución de su territorio ancestral, nos pareció pertinente contextualizar e historizar este evento, tomándolo como un hito en un largo recorrido, no exento de obstáculos y dificultades presentados tanto desde afuera como desde el interior de la propia comunidad.

109 Considerando la potencia de la "amnesia social", la cual describe los mecanismos más poderosos empleados por la empresa colonial para re-estructurar espacio-temporalmente a las sociedades andinas (Abercrombie, 1998) para entender los objetivos de la fundación de los Estados nacionales en nuestro continente, la reflexión histórica de los mismo actores resulta ser la herramienta más poderosa que motoriza “...un proceso de interpretación de evidencias del pasado, que conlleva inmediatos referentes históricos a través del uso de imágenes y metáforas; ambas, la narrativa y el ritual, ligando el pasado con la contemporaneidad a que hacen referencia" (Rappaport en Isla, 2002, p. 126).

110 Esta revisión permite seguir indagando de qué manera y en qué contextos (re)surgen y se resignifican ciertas prácticas de los pueblos indígenas, que si bien han sido utilizadas con fines políticos durante las últimas décadas, no se puede negar su persistencia (aunque por momentos obligadamente silenciosa) a lo largo de los siglos.

\section{Anexos}

Tabla N ${ }^{\circ}$, Propietarios de Finca Santiago 1894-1997. 


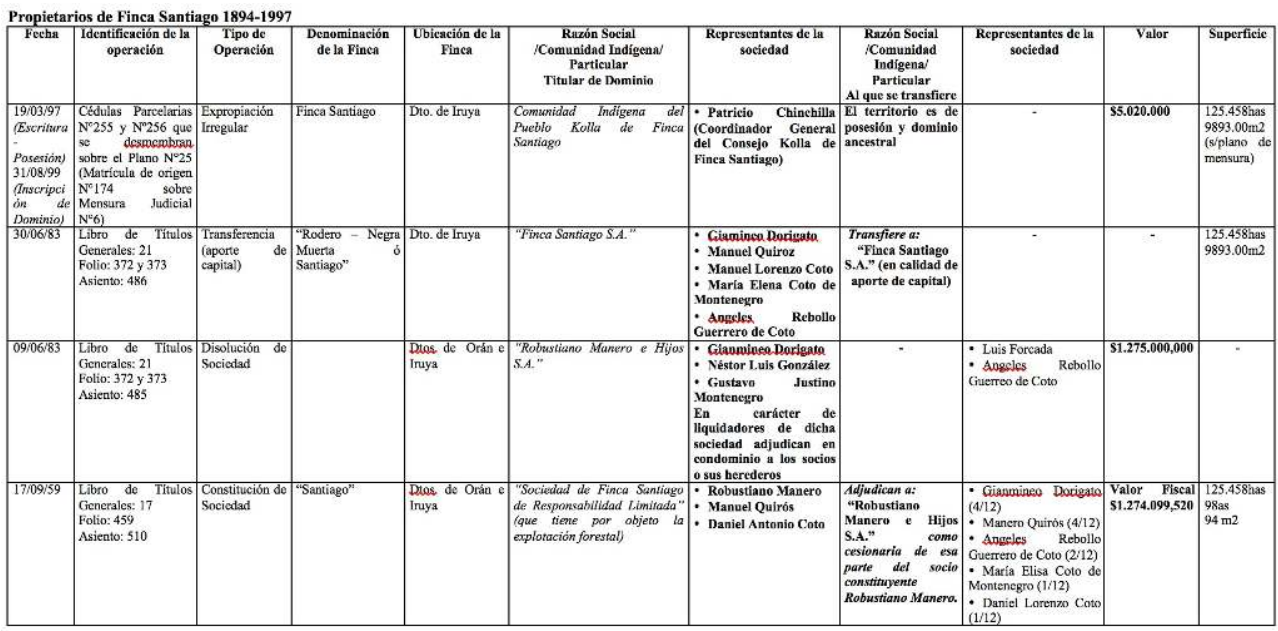

\begin{tabular}{|c|c|c|c|c|c|c|c|c|c|c|}
\hline Fecha & $\begin{array}{l}\text { Identificación de } \\
\text { la operación }\end{array}$ & $\begin{array}{l}\text { Tipo de } \\
\text { Operación }\end{array}$ & $\begin{array}{l}\text { Denominatión } \\
\text { de la Finea }\end{array}$ & $\begin{array}{l}\text { Ubicatiön de las } \\
\text { Finea }\end{array}$ & $\begin{array}{c}\text { Razón Social } \\
\text { /Comunidad Indigena } \\
\text { Particular } \\
\text { Titular de Dominio }\end{array}$ & $\begin{array}{c}\text { Representantes de la } \\
\text { socicdad }\end{array}$ & $\begin{array}{c}\text { Razón Social } \\
\text { /Comunidad } \\
\text { IIdigienal/ } \\
\text { Particular } \\
\text { Al que setransfiere }\end{array}$ & $\begin{array}{l}\text { Representantes de las } \\
\text { sociedad }\end{array}$ & Valor & Superficie \\
\hline $19,088 / 59$ & $\begin{array}{l}\text { Libro de Tifulos } \\
\text { Genendies: } 17 \\
\text { Folio: } 455 \\
\text { Asiento: } 505\end{array}$ & Compra venta & $\begin{array}{l}\text { "Rodern" y "Negrat } \\
\text { Muerta" o } \\
\text { "Surtiggo" }\end{array}$ & \begin{tabular}{|l|} 
Dtas de Oran c \\
Iruya
\end{tabular} & $\begin{array}{l}\text { "Sociedad Finca Santiago de } \\
\text { Responsabilidad Limitada a" }\end{array}$ & $\begin{array}{l}\text { Robustiann Manero } \\
\text { Manuel Quirós }\end{array}$ & & \begin{tabular}{|l|l} 
Manucl Quiros \\
Daniel Antonio Coto
\end{tabular} & $\$ 2.534 .358$ & $\begin{array}{l}125.458 \text { has } \\
98 \text { 9s } \\
94 \mathrm{~m} 2\end{array}$ \\
\hline $17 / 07 / 51$ & 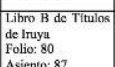 & Compra venta & $\begin{array}{l}\text { "Rodem" y "Ncgrat } \\
\text { Muera" " } \\
\text { "Suntiago" }\end{array}$ & \begin{tabular}{|l|} 
Dtas de Orản c \\
lnyya
\end{tabular} & $\begin{array}{l}\text { Sociedad de Regponsabilidad d } \\
\text { Limitada "Maneroy Quirios" }\end{array}$ & $\begin{array}{l}\text { Robustiano Manero } \\
\text { Manuel Quiris }\end{array}$ & - & \begin{tabular}{|l|} 
Manucl Quiris \\
Dannicl Antonio Coto \\
Don
\end{tabular} & $\$ 2.534 .358$ & $\begin{array}{l}125.45 \mathrm{Shas} \\
\text { 98 } \\
94 \mathrm{~s} 2\end{array}$ \\
\hline $20 / 1 / 28$ & 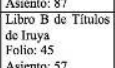 & Compra venta & $\begin{array}{l}\text { "Rodere" y "Negrat } \\
\text { Mucrat" } \\
\text { "Santiago" }\end{array}$ & $\begin{array}{l}\text { Dhos de Otán e } \\
\text { Iruya }\end{array}$ & 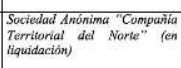 & $\begin{array}{l}\text { - José Marin Oudcux } \\
\text { (representante para este } \\
\text { acto) }\end{array}$ & 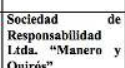 & 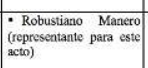 & $\$ 2.500 .000$ & $\begin{array}{l}125.458 \text { ias } \\
98 \text { as } \\
94 \mathrm{~m} 2\end{array}$ \\
\hline $12008: 26$ & $\begin{array}{l}\text { LAsicnto: } 57 \\
\text { Libro F de Títulos } \\
\text { de Oran } \\
\text { Folio: } 125 \\
\text { Asiento: } 249\end{array}$ & Venta & $\begin{array}{l}\text { "Rodero" y "Negra } \\
\text { Muerat" } \\
\text { "Santiago" o }\end{array}$ & 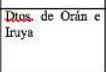 & $\begin{array}{l}\text { Sociedad "Patron Costas y } \\
\text { Companitia" }\end{array}$ & $\begin{array}{l}\text { Juan Patrón Costas } \\
\text { (socio representante) }\end{array}$ & 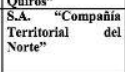 & $\begin{array}{|ll|}\text { - Juun } & \text { Mossciano } \\
\text { (Presidente) } \\
\text { - Higinio } \\
\text { (Sceretario) }\end{array}$ & $\$ 400.000$ & $\begin{array}{l}125.458 \text { ias } \\
998 \text { sis } \\
94 \mathrm{~m} 2\end{array}$ \\
\hline $06099: 08$ & $\begin{array}{l}\text { Libro C de Titulos } \\
\text { de Onin } \\
\text { Folio: } 118 \\
\text { Asiento: } 197\end{array}$ & $\begin{array}{l}\text { Venta ef } \\
\text { Hipoteca }\end{array}$ & $\begin{array}{l}\text { "Roden" y "Ncgra } \\
\text { Muera" }\end{array}$ & \begin{tabular}{|l|} 
Deparamamentos \\
de Orine elruyay
\end{tabular} & \begin{tabular}{|l} 
Sociedad \\
Compaña"
\end{tabular} & $\begin{array}{l}\text { Miguel Fleming } \\
\text { Ooctar Robustiano } \\
\text { Patrón Costas }\end{array}$ & $\begin{array}{l}\text { Juan Patrón } \\
\text { Costas }\end{array}$ & & 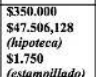 & \\
\hline $05 / 09: 06$ & $\begin{array}{l}\text { Libro C de Trtulos } \\
\text { de Orin } \\
\text { Folio: } 118 \\
\text { Asiento: } 196\end{array}$ & $\begin{array}{ll}\text { Ventas } & \text { can } \\
\text { Hipotecas } & \end{array}$ & $\begin{array}{l}\text { "Rodem" o "Negra } \\
\text { Muera" }\end{array}$ & $\begin{array}{l}\text { Dxos de Orin c } \\
\text { lruya }\end{array}$ & Francisco A. Terrones & & $\begin{array}{ll} & \text { Miguel } \\
\text { Fleming } \\
\text { Robustiano } \\
\text { Patrón Costas }\end{array}$ & & $\begin{array}{l}\$ 60.000 \\
\$ 300 \\
\text { (estampillado) } \\
\text { \$300 (papd de } \\
\text { multa } \\
\text { pagados) }\end{array}$ & - \\
\hline $23 / 05 / 1894$ & $\begin{array}{l}\text { Libro A de Titulos } \\
\text { de riya } \\
\text { Folio } \begin{array}{l}\text { No: } 19 \\
\text { Asiento } 50\end{array}\end{array}$ & $\begin{array}{l}\text { Compra venta } \\
\text { con Hipoteca }\end{array}$ & $\begin{array}{l}\text { "Roden" o"Ncgra } \\
\text { Muerra" }\end{array}$ & Dro. de Inyya & Banco Hipotecario Nacional & - & $\begin{array}{ll}\begin{array}{l}\text { Franciscer } \\
\text { Terrones }\end{array} & A \\
\end{array}$ & & 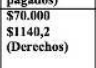 & 170.50 has \\
\hline
\end{tabular}




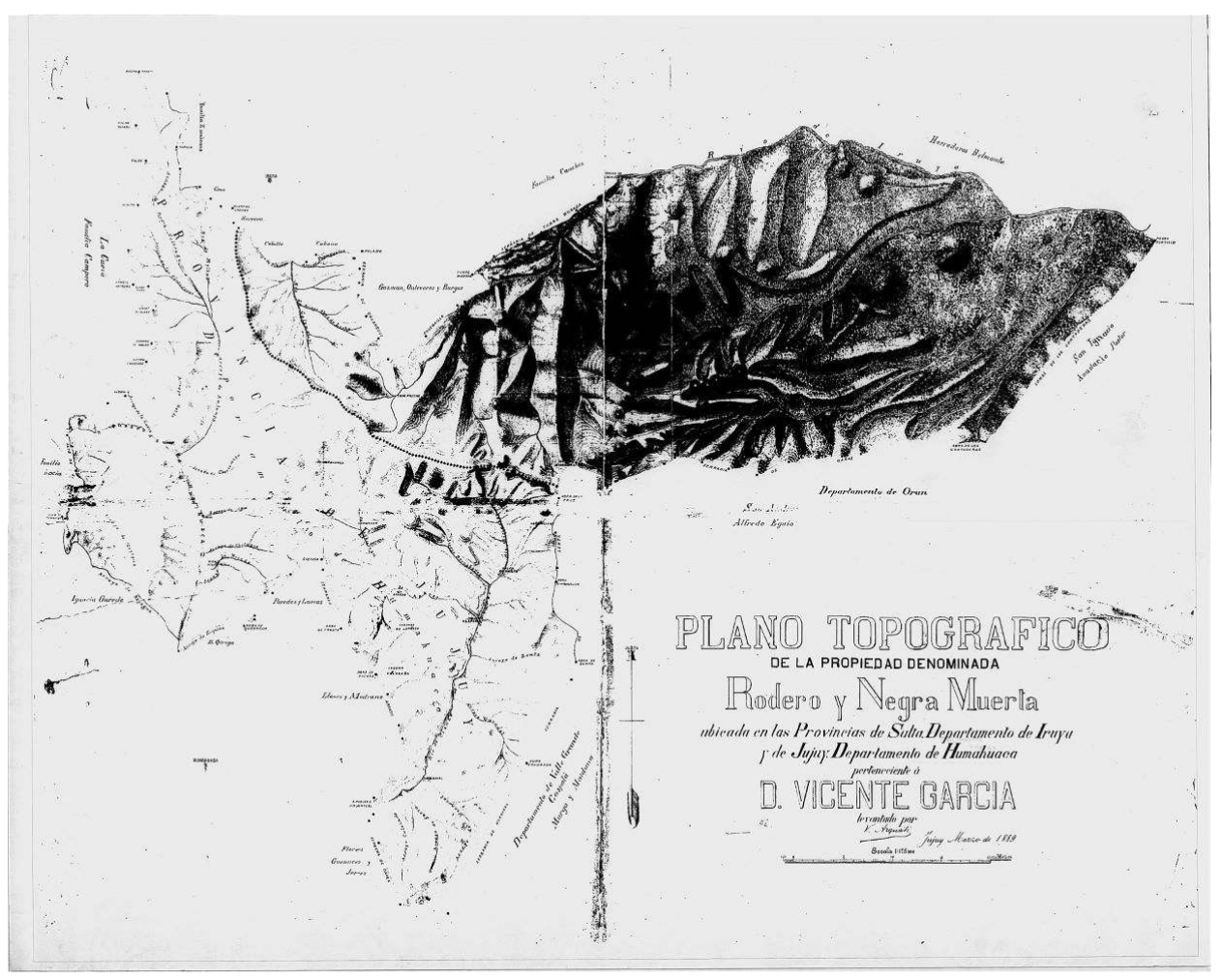

Mapa N4: Plano Topográfico de la propiedad denominada "Rodero y Negra Muerta" ubicada en las provincias de Salta, departamento de Iruya y Jujuy, departamento de Humahuaca, perteneciente a Don Vicente García, marzo de 1889.

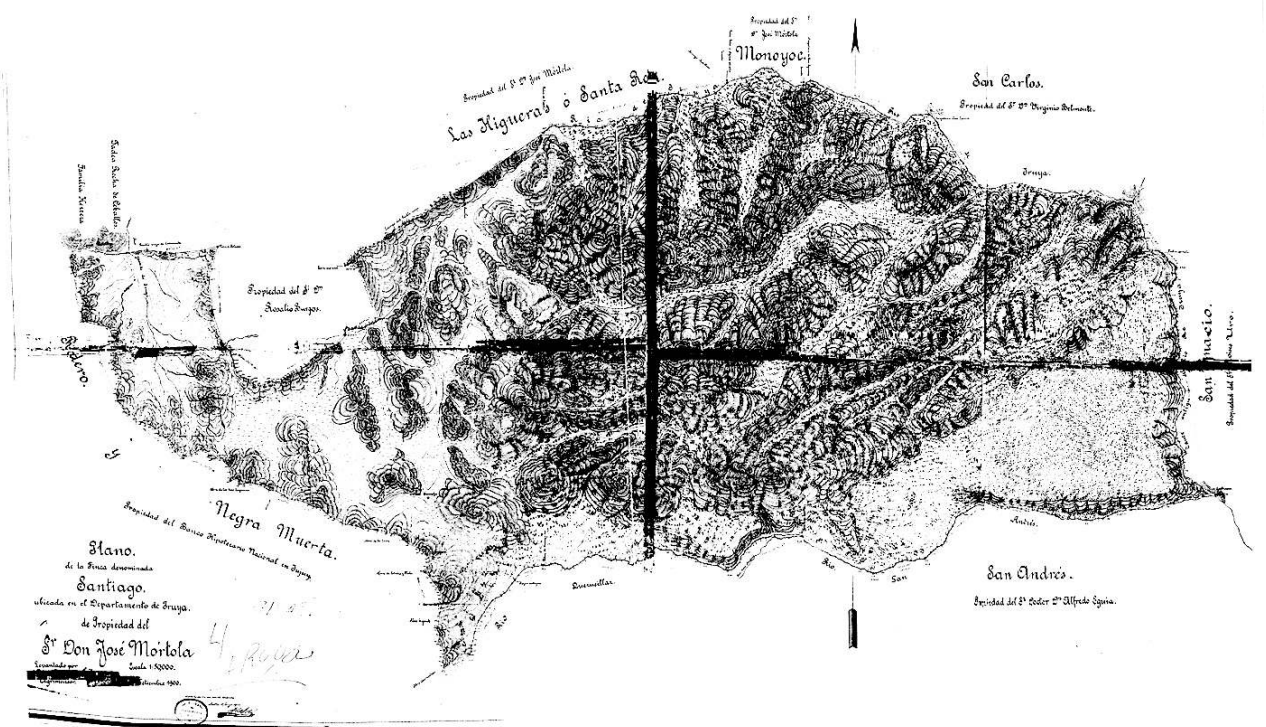

Mapa N5: Plano de septiembre 1900, el plano de la propiedad "Santiago" (departamento de Iruya), de Don José Mórtola con el nombre del agrimensor tachado. 


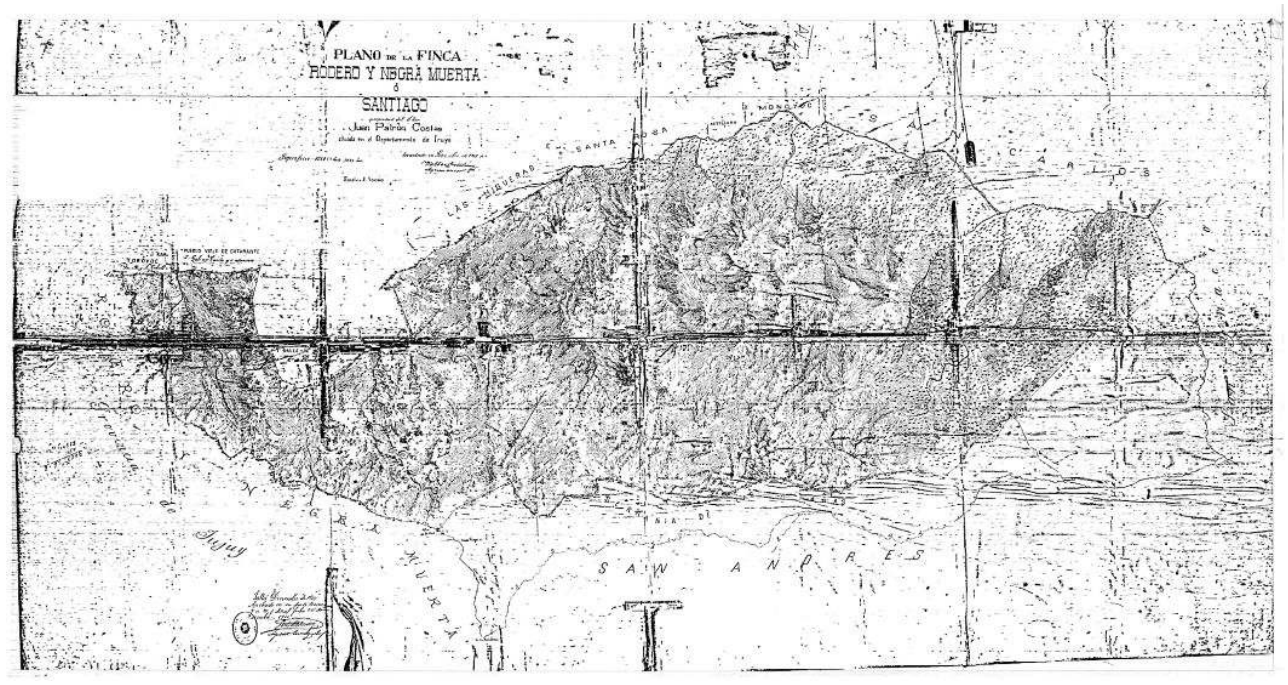

Mapa N6: Plano de la Finca "Rodero o Negra Muerta" o "Santiago" propiedad del señor Juan Patrón Costas, situada en el departamento de Iruya, levantada en septiembre de 1908. Walter Hessling, 24/11/1910, Depto. Topográfico.

\section{BIBLIOGRAFÍA}

Abercrombie, T. (1998). Pathways of Memory and Power. Ethnography and History Among the Andean People. Madison: The University of Wisconsin Press.

Argentina (1872).Primer Censo de la República Argentina verificado en los días 15, 16 y 17 de septiembre de 1869 bajo la Dirección de Diego G. de la Fuente, Buenos Aires: Imprenta del Porvenir.

Argentina (1898). Segundo Censo de la República Argentina, mayo 10 de 1895, Buenos Aires: Taller Tipográfico de la Penitenciaría Nacional (3 Tomos).

Bisio, R.H. y Forni, F. (1976). Economía de enclave y satelización del mercado de trabajo rural. El caso de los trabajadores con empleo precario en un ingenio azucarero en el noroeste argentino. Desarrollo Económico. Revista de Ciencias Sociales, 61,16-61.

Fandos, C. A. (2014). Enfiteutas, propietarios y arrendatarios en el departamento de Humahuaca. Estructura social y distribución de la riqueza en la década de 1860. Dossier, Estudios Sociales del NOA, 14,41-61.

Fandos, C. A. (2015). Los "sagrados derechos" en cuestión. El conflicto por la tierra en las haciendas de la Quebrada de Humahuaca (Jujuy, Argentina), décadas de 1870 y 1880. Andes, 26 (January-June).

Fidalgo, A. (1988). ¿De quién es la Puna? Jujuy: Edición del autor.

Hocsman, D. (2000). El regreso a la tierra. Estrategias territoriales y economía doméstica en los valles intermontanos de la cordillera oriental (San Isidro - Salta). (Tesis de Maestría), Programa 
de Postgrado en Antropología Social, Facultad de Humanidades y Ciencias Sociales, Universidad Nacional de Misiones.

Isla, A. (1992). (comp.) Sociedad y articulación en las tierras altas jujeñas. Crisis terminal de un modelo de desarrollo, Buenos Aires: Proyecto ECIRA - MLAL.

Isla, A. (2002). Los usos políticos de la identidad. Indigenismo y Estado. Buenos Aires: Editorial de las Ciencias.

Madrazo, G. B. (1982). Hacienda y encomienda en los Andes. La Puna argentina bajo el Marquesado de Tojo. Siglos XVII a XIX. Buenos Aires: Fondo Editorial.

Paz, G. (1989). Resistencia y rebelión campesina en la Puna de Jujuy, 1850-1875, Buenos Aires: Documentos Cedes, 22 .

Paz, G. (1992). Campesinos, Terratenientes y Estado. Control de tierras y conflictos en la puna de Jujuy a fines del siglo XIX. En A. Isla (Comp.), Sociedad y articulación en las tierras altas jujeñas. Crisis terminal de un modelo de desarrollo, (pp. 219-235). Buenos Aires: Proyecto ECIRA - MLAL.

Reboratti, C. (1998). El Alto Bermejo. Realidades y conflictos. Buenos Aires: Editorial La Colmena.

Rutledge, I. (1992). La rebelión de los campesinos indígenas de las tierras altas del norte argentino, 1872-75. En A. Isla (Comp.) Sociedad y articulación en las tierras altas jujeñas. Crisis terminal de un modelo de desarrollo, (pp. 237-255). Buenos Aires: Proyecto ECIRA - MLAL.

Salta, Primer Censo de la Provincia de Salta (Año 1865), 237-255.

Sánchez, S. (2003). Un viaje entre la historia y la memoria: los 'ossa' jujeños, Anuario de Estudios Americanos, Tomo LX, 1.

Sánchez, S. y Sica, G. (1990). La frontera oriental de Humahuaca y sus relaciones con el Chaco, Bulletin de l' InstitutFrançais d' Etudes Andines, 19(2), 469-497.

Sica, G. (2016). Procesos comunes y trayectorias diferentes en torno a las tierras de los pueblos de indios de Jujuy. Siglo XVI al XIX. Revista del Museo de Antropología, 9 (2), 171-186.

Teruel, A. y Fandos C. (2009). Procesos de privatización y desarticulación de tierras indígenas en el norte de Argentina en el siglo XIX. Revista Complutense de Historia de América, 35,233-25.

Tizón, H. (1969). Fuego en Casabindo. Buenos Aires: Ediciones Galerna.

Weinberg, M. (2004a). Identidad y Política. Formas de organización en la Comunidad Kolla de Finca Santiago (Iruya-Salta). (Tesis de Licenciatura) Facultad de Filosofía y Letras, Universidad de Buenos Aires.

Weinberg, M. (2004b). Identidades y organización política en la Comunidad Kolla de Finca Santiago. Iruya- Salta, Estudios sociales del NOA 7(7), 43-65.

Weinberg, M. (2005). Identidad étnica y organización política en un espacio local y sus relaciones con el Estado. Una comunidad kolla del Noroeste argentino. En M.I. Fernández, y O. Scher (Coords.), Diversidad Cultural. Múltiples miradas del tiempo presente, (pp. 135-158). Buenos Aires: Asociación Argentina de Estudios Canadienses.

Weinberg, M. (2013). Back to National Development: State Policies and Indigenous Policies in Northwestern Argentina after the 2001 Crisis. (PhD Dissertation). State University of New York at Binghamton University: ProQuest-UMI.

Weinberg, M. y Mercolli, P. (2015). Azúcar Amargo: Historias de San Martín de Tabacal. En L. Córdoba, F. Bossert y N. Richard (Eds.), Capitalismo en las selvas. Enclaves industriales en el 
Chaco y Amazonía indígenas (1850-1950), (pp. 93-106). San Pedro de Atacama: Ediciones del Desierto.

Weinberg, M. y Mercolli, P. (2016). Sweet Death. Indigenous Labor Exploitation in the San Martín de Tabacal Sugar Mill, Argentina. Cultural Studies, 31(1), 70-92.

Zanolli, C. (2005). Tierra, encomienda e identidad: Humahuaca (1540-1638). Buenos Aires: Sociedad Argentina de Antropología.

\section{NOTAS}

1. Esta investigación estuvo financiada por el Subsidio de Investigación Sandra Sánchez sobre Historia y Antropología del Mundo Andino. Fondazione Sandra Sánchez - Padova, Italia y FLACSO Argentina, 2005-2006. Vaya en el título, un homenaje a Sandra Sánchez (2003) "Un viaje entre la historia y la memoria: los 'ossa' jujeños" en: Anuario de Estudios Americanos Tomo LX, 1. Sevilla, España. Mientras se terminaba el proceso de edición del presente artículo, la triste noticia del fallecimiento de Alejandro Isla me atravesó. Inicialmente le agradecía a él, junto con Gustavo Paz, por haberme orientado tanto durante el proceso de trabajo en archivos como durante la escritura del informe que dio como resultado este artículo. Ahora, aun acostumbrándome a su ausencia, quiero dedicarle el escrito ya que fue Alejandro quien me apoyó desde el inicio en mi largo andar por Finca Santiago. Finalmente, agradezco la minuciosa lectura y comentarios realizados por los dos evaluadores externos.

2. En otros trabajos se desarrollan problemáticas más contemporáneas que son resultado de investigaciones etnográficas en la misma región (Weinberg 2004a, 2004b, 2005, 2013).

3. La información analizada en este apartado fue obtenida tanto en Cédulas Parcelarias como en los Libros de Catastro de la Dirección General de Inmuebles de la provincia de Salta. Los planos están incorporados en el Anexo, así como el cuadro resumen citado en el apartado anterior (Cuadro Propietarios de Finca Santiago 1884- 1997).

4. Se ha trabajado extensamente en el estudio sobre explotación de mano de obra indígena en el ingenio San Martín de Tabacal, por lo que no se detallará en el presente artículo (ver Weinberg, 2004a y b, 2013; Weinberg y Mercolli, 2014, 2016).

5. En las décadas siguientes mermó estrepitosamente la demanda de mano de obra debido a la mecanización de la industria azucarera.

6. El término ayllu ha sido tomado tanto de las entrevistas realizadas a lo largo de los años así como del Estatuto General de la Comunidad Kolla de Finca Santiago.

7. Por supuesto se hace alusión al período estudiado en este trabajo (siglo XX), no desconociendo en lo más mínimo el maltrato sufrido por los pueblos originarios desde siglo atrás.

8. Primer y Segundo Censo de la República Argentina, años 1869 y 1895. Agrupación provincias norte, departamento de Iruya, $\mathrm{N}^{\circ}$ Vol. $347 \mathrm{y} \mathrm{N}^{\circ}$ Vol. 1158 respectivamente. Sala IX, Archivo General de la Nación.

9. De este segundo grupo, debe decirse que los poblados han sido casi completamente abandonados debido a las migraciones o a la desaparición de los pueblos por la crecida del río Iruya a lo largo de los años.

10. Carpeta de Gobierno, Archivo Histórico de Salta.

11. La totalidad de la documentación revisada en este apartado fue obtenida en el Archivo del Arzobispado de Salta, carpeta Iruya.

12. El paraje Tres Morros está ubicado dentro de los límites de Finca Santiago. 
13. El paraje Limoncito está fuera de los límites de la Finca, a pesar de lo cual muchos pobladores de las comunidades que sí pertenecen al territorio estudiado tienen puestos familiares allí.

14. Tanto Bibiano como Julián figuran en el censo de 1895.

15. Liberata Anagua figura en el censo de 1895.

\section{RESÚMENES}

El objetivo del presente análisis es presentar una serie de documentos hallados en relación a la historia de la Comunidad indígena kolla de Finca Santiago, primera en recibir reconocimiento legal y la devolución territorial posterior a la Reforma Constitucional de 1994 en Argentina. Se presentan aquí censos, mensuras, títulos de propiedad y notas dirigidas a jerarquías eclesiásticas y políticas, confeccionados entre fines del siglo XIX y a lo largo del siglo XX. De alguna manera, se considera que dichos archivos permiten ahondar en una historia de disputa territorial y de lucha por reconocimiento estatal, más allá de un contexto tanto mundial como regional que favoreció la re-emergencia étnica en los años noventa.

The objective of the present analysis is to introduce a series of documents related to the history of the Kollacommunity of Finca Santiago, which was the first to receive legal recognition and territorial restoration after the Constitutional Reform of 1994 in Argentina. Censuses, surveys, titles of property and notes directed to ecclesiastical and political hierarchies composed between the end of $19^{\text {th }}$ century and all throughout the 20th century. To some extent, it is considered that these archives allow us to deepen into a history of territorial dispute and struggle for state recognition, beyond a global and regional context that favored ethnic re-emergence during the nineties.

\section{ÍNDICE}

Palabras claves: Memoria, territorio, pueblos indígenas, noroeste argentino

Keywords: Memory, territory, indigenous peoples, northwestern Argentina

\section{AUTOR}

\section{MARINA WEINBERG}

Universidad Católica del Norte, Instituto de Arqueología y Antropología, San Pedro de Atacama, Chile

Correo electrónico: marina.weinberg@unc.cl 